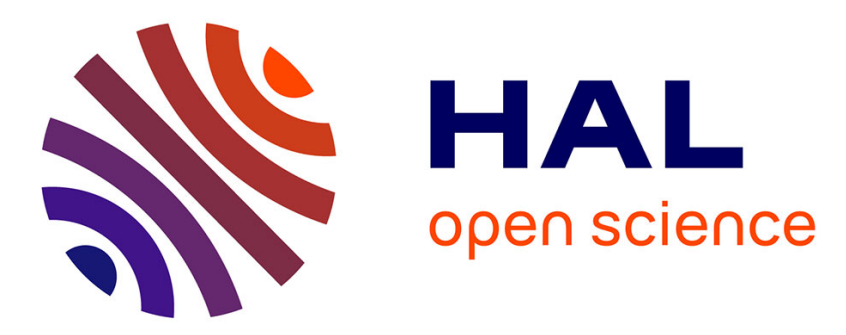

\title{
Creating Contextualised Usability Guides for Web Sites Design and Evaluation
}

Céline Mariage, Jean Vanderdonckt

\section{To cite this version:}

Céline Mariage, Jean Vanderdonckt. Creating Contextualised Usability Guides for Web Sites Design and Evaluation. 5th International Conference on Computer-Aided Design of User Interfaces, Jan 2004, Funchal, Portugal. pp.145-156, 10.1007/1-4020-3304-4_12 . hal-01319624

\section{HAL Id: hal-01319624 \\ https://hal.science/hal-01319624}

Submitted on 25 May 2016

HAL is a multi-disciplinary open access archive for the deposit and dissemination of scientific research documents, whether they are published or not. The documents may come from teaching and research institutions in France or abroad, or from public or private research centers.
L'archive ouverte pluridisciplinaire HAL, est destinée au dépôt et à la diffusion de documents scientifiques de niveau recherche, publiés ou non, émanant des établissements d'enseignement et de recherche français ou étrangers, des laboratoires publics ou privés. 


\title{
Chapter 12
}

\section{CREATING CONTEXTUALISED USABILITY GUIDES FOR WEB SITES DESIGN AND EVALUATION}

\author{
Céline Mariage and Jean Vanderdonckt \\ Institut d'Administration et de Gestion, Université catholique de Louvain \\ Belgian Lab. of Computer-Human Interaction (BCHI) \\ Place des Doyens, 1 - B-1348 Louvain-la-Neuve (Belgium) \\ E-mail:jean.vanderdonckt@uclouvain.be \\ Tel.: +32-10-47 \{8391, 8525\}-Fax: +32-10-478324
}

\begin{abstract}
This work addresses the problem of creating usability guides for web sites design and evaluation. We present a web-distributed tool, called MetroWeb, to help web designers create and/or access to contextualised usability knowledge during the whole design process, in order to develop user-centred applications. The developer creates her own usability knowledge bases, which can be composed of other usability bases diffused by the tool, and uses this knowledge when designing and/or evaluating her web site. The usability knowledge forms a semantic network, in which various searching paths linked to user-centred design and evaluation are represented.
\end{abstract}

Keywords: User-centred design and evaluation, Tools for working with guidelines, Web usability guides.

\section{INTRODUCTION AND MOTIVATIONS}

Usability knowledge exists in many forms today, both and explicitly within people, guides, and tools: guidelines, patterns, design rules, conventions, and standards. Although this knowledge is supposed to be used continuously throughout the development life cycle, there is often a gap between the constitution of this knowledge and its true usage during design and evaluation. This gap is also often reflected in the existence of separate, independent processes and tools intended to support design and evaluation at the same time. For instance, software exist that capitalise usability knowledge to 
be used by developers, but once evaluators use the knowledge capitalised by one of these tools in order to assess the usability of the developed user interface (UI), the tool stops and another tool starts, thus preventing members of the development team to link usability problems with related knowledge and to accumulate this knowledge as the organisation experience is growing. In addition, each tool typically remains focused on one aspect at a time: an online style guide only provides guidelines, but no testing of them, some UI evaluators can perform testing, but with little or no access to the usability knowledge.

There is almost no task-based tool to support the constitution of a style guide among stakeholders so as to share it with developers afterwards during the development life cycle. Moreover, the process of progressively introducing guidelines in a standard remains mostly manual, without any tool support.

To address the above shortcomings, a generic tool is presented that permits to create a contextualised usability guide, which represents a set of guidelines linked to significant usability knowledge, like an interface object on which the guideline can be applied, or an evaluation method that is able to assess the guideline. The usability knowledge can be expanded at any time, disseminated at any time and explicitly used during design and evaluation in a continuous way, shared by everyone implied in the web site development.

Although the tool presented can manage usability knowledge about any potential type of interface and a large spectrum of evaluation methods, we focus it on UIs for the web with heuristic or expert-based evaluation [1]. The tool is web-distributed to manage usability knowledge in a flexible and autonomous manner that can be run on multiple computing platforms.

Our main objectives are (1) to provide a tool responding to design questions with guidelines and resources exploitation, (2) to permit to automate searching paths related to user-centred design and evaluation process, (3) to support the usability guide creation task.

The paper is organised as follows: Section 2 reports on the most significant pieces of work related to the main goal. Section 3 presents the semantic network defining the fundamental usability concepts required to be manipulated in a usability knowledge base, in regard to searching paths linked to usability evaluation. Section 4 explains how to create a usability style guide with the tool. Section 5 presents how to use the guide in web site development. Section 6 reports on the design and development of the tool. Section 7 summarises the main points of the paper and presents some future work. 


\section{RELATED WORK}

In the 'Tools for Working with Guidelines' (TFWWG) approach [11], tools were developed for accessing and retrieving guidelines organised either as a database or hypertext [4], in order to diffuse and promote usability knowledge to use during UI design.

First, usability guides were diffused on paper, but rapidly appeared guides on hypertext support. Hyperlinks joined guidelines to resources (e.g. references or ergonomic criteria).

After that, hypermedia permitted to usability guides to link usability knowledge to illustrative examples, presented in various format like screen shots or video sequences.

These first supports did not permit efficacy information research. For that reason appeared tools managing usability knowledge bases and permitting efficacy research information and structure usability knowledge. Some of these tools are: i) SIERRA [9,12], which manages a usability knowledge database used with a hypermedia system; ii) Sherlock [4], which manages usability guidelines by a client-server system, evaluating automatically some guidelines or offering advice about how to solve detected design problems; iii) GUIDE [5], which permits to manage a guidelines base, linking guidelines used to a particular application and storing these experiences in cases in order to be reused by case-based reasoning; iv) the TELE-environment [3], which consists of a multimedia learning environment for the web, managing interactive examples and cases linked to usability guidelines, in order to help developers understand and apply guidelines during the web design.

Unfortunately, these tools manage only one base at a time and for that reason remain too rigid in a development cycle. Moreover, there do not support continuous evaluation usage, except Sherlock [4] that is supporting some steps of the evaluation process. User-centred design is not really supported by these tools, because the guidelines contextualisation is poor. Various design questions are not covered by the tools, e.g. "which are the guidelines appropriated to this context of use, in this particular development phase and linked to some ergonomic criteria".

We present in this paper the MetroWeb tool that enables the management of multiple guidelines bases with a more precise contextualisation of the guidelines. This contextualisation is guided by a semantic network managing possible searching paths needed in web usability design and evaluation. Moreover, many users are able to share the tool (evaluator, designer, developer, etc.). 


\section{THE METROWEB SEMANTIC NETWORK}

This section presents the semantic network we want to support with the MetroWeb tool, in order to respond to design questions. In fact, it's frequent that, during the user-centred design cycle of the web site, the designer needs to assess to particular guidelines, e.g. guidelines dedicated to the elaboration of forms. Guidelines can also be appropriated to such a development phase, like the specifications. The designer can be interested in which evaluation methods she can use to assess a set of guidelines. When she decides to choice such interaction object to put in a web page, she can need to access to the guidelines linked to this object. If she wants to assess ergonomic criteria in her site, like consistency e.g., she needs to know which guidelines are linked to these criteria. In parallel, to which criteria are linked such guidelines is important to know. In a particular context of use, like the use of the web site by people with disabilities, particular guidelines (e.g., accessibility guidelines), have to be respected. Moreover, the designer needs to access to illustrative examples of the guidelines, references or related guidelines. The complete information related to guidelines is summarised in Fig. 1. The semantic network we define is aimed to respond to these questions.

The core concept of the MetroWeb network is the guideline. A guideline consists of a design and/or evaluation principle to be observed to get and/or guarantee a usable user interface [2]. Guidelines can be found in many different formats with contents varying both in quality and level of detail, ranging from ill-structured common sense statements to formalized rules ready for automatic guidelines checking [6]. A guideline can be characterised, or contextualised, by other concepts like ergonomic criteria, linguistic level or model.

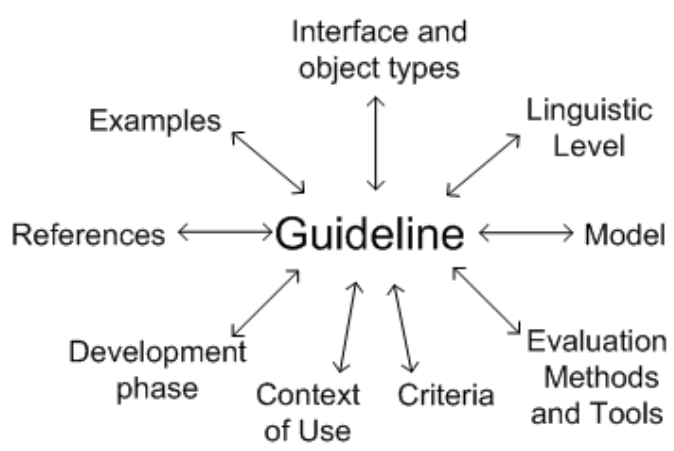

Figure 1. Fundamental Concepts of MetroWeb.

The organisation of fundamental concepts around the guideline enables browsing the knowledge base from multiple entry points toward any target information in a reversible way: for instance, from task model to guidelines 
and vice versa. An entity-relationship schema exists that structures considered usability concepts into 40 entities and 34 relationships.

Ergonomic criteria are criteria that lead to an elaborated, efficient, sophisticated, user friendly UI [2]. Nielsen's linguistic model [7] separates human-computer interaction into seven layers ranging from the highest level (the closest of the human world) to the lowest level (the closest to the computer world). In a guideline evaluation process, other interface information has to be specified: interface and object types, context of use, development phase. Indeed, evaluator needs more information about the guideline than the guideline itself. For example, she needs to know to which types of user, task and environment the guideline applies. This information forms the context of use [5]. The evaluation methods and tools must also be specified, in order to illustrate to the evaluator how to resolve the usability problems encountered. Positive and negative examples and bibliographic references reinforce also the evaluation when present. If the evaluator needs to assess a particular interactive object of a particular interface, she can consult all the guidelines linked to that particular point. If an evaluator wants to evaluate a specified guidelines base in the evaluated interface, she can consult the evaluation methods and tools permitting guidelines base assessment. Navigation can be made by whatever input point and by direct manipulation. These concepts are structured in a semantic network. This network allows different types of reasoning because it contains several facets [8]:

- Definitional: any entity of interest is described by its own definition in the guidelines base, i.e. by the attributes. Moreover, relationships link entities, e.g., the entity Web-Site is a subtype of the super type UI-type and is the super type of Intranet, Extranet and Internet. Decomposition relation can also link objects to sub-objects, e.g. a Concrete Interaction Object (CIO) [10] can be composed by other CIOs. In this way, usability knowledge is attached to the highest level of application possible.

- Assertional: assertions can be added between guidelines, e.g., the guideline stating that, in a web site, each image should have an alternative text is no more valuable when another image with the same alternative text stays next to the image.

- Implicational: implications can be incorporated between contents. For example, if you consider a guideline, then you also need to check if it respects other guideline(s) implied by this one, e.g., a guideline stipulating that web site look must be consistent in the entire application applies to all the objects of the interface. To evaluate this, the consistency has to be assessed in each web page of the web site. For that reason, each guideline part of the consistency criteria must be assessed in each page of the web site to evaluate. If the evaluation concerns several web sites, we must 
verify each application page. The consistency evaluation is called interapplication, and no more intra-application.

- Executable: in our network, associations between evaluation tools and guidelines are specified so that any usability knowledge content that can be automated is delegated to a tool to be executed.

- Pedagogic: the usability knowledge managed by MetroWeb, e.g. evaluation methods and tools, can generate tutorial, guided tours, pro's and contra's argumentation of the design cases, and teaching of design through examples. This pedagogic facet is shared by other TFWWGs $[3,11]$.

These 5 facets permit to support different searching paths linked to usercentred design.

\section{CREATING USABILITY GUIDES WITH METROWEB}

Once the fundamental aspects are known, there is a need to identify interactive tasks that manipulate this knowledge in a user-centred way. Our tool permits to create usability guides to be used during the web site development. In this section we develop the different tasks to hold to get a usability guide with the tool. We present also the evaluation tasks involving the use of the usability guides. First the creation itself of usability guides is decomposed into several tasks (Fig. 2): collecting, organisation and incorporation of the guidelines into a method.

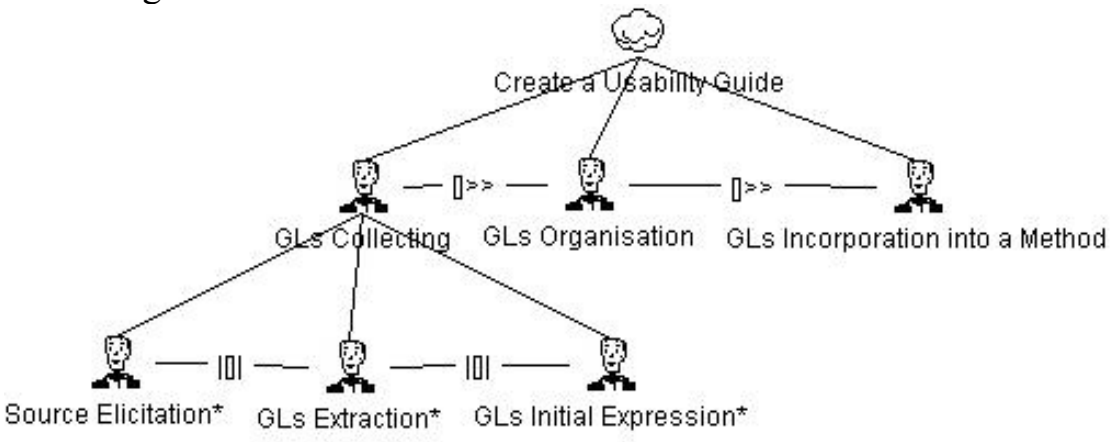

Figure 2. Tasks of Usability Guide Creation.

The collection of the guidelines depends on the user's needs. Does the user want to use existing usability guides or create her own? She can also use existing sources to create her guide, contextualised to the organisation needs (types of web sites analysed, development phases to cover, evaluation objectives like code verification of home pages or semantic analysis, etc.). Our tool permits the management of multiple guidelines bases, whatever the 
source. The guidelines collection can be divided in source elicitation, guidelines extraction and initial expression.

The organisation of the guidelines is the main goal of the tool. The guideline itself is structured on a hierarchy. Each guidelines base created can manage sections and subsections, as deep as needed. Fig. 3 shows the implemented interface: the left part contents hierarchy in one base, and the right part shows the guidelines belonging to one subsection. The guidelines details appear when the user selects a guideline.

Contextualisation of the guidelines is permitted by the semantic network supported by the tool. All the themes presented in Fig. 1 can contextualise the guidelines and form a contextualised usability guide. For example, an organisation that wants to develop usability guides about Intranet will collect specific guidelines linked to this topic.

The incorporation of the guidelines into a method is largely supported by our tool. In fact, it supports heuristic inspection that assesses UIs in comparison with a list of principles or guidelines. A heuristic inspector can use MetroWeb to access to the guidelines she wants to verify in the interface. Links to usability knowledge reinforce the applicability of the guidelines. Even if heuristic inspection is supported by the tool, other methods can be linked to guidelines, in order to guide the evaluation process, whatever the method used.

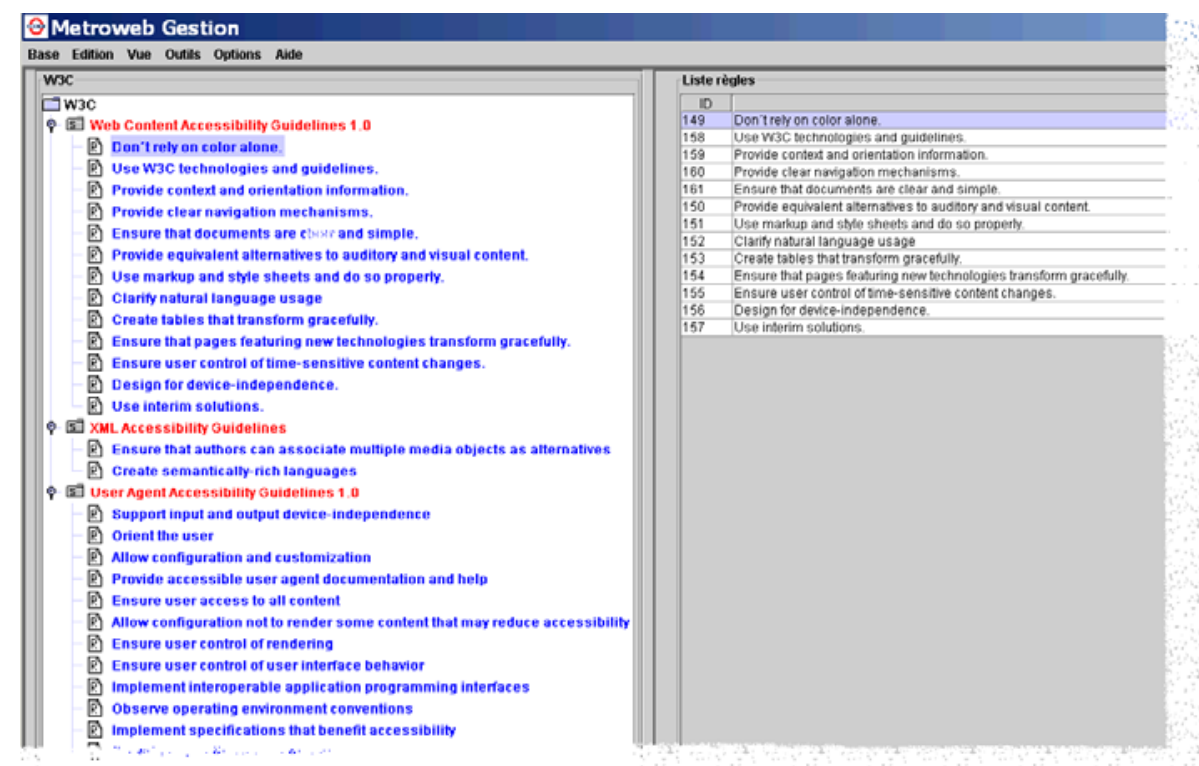

Figure 3. Guidelines hierarchy. 


\section{USING USABILITY GUIDES IN WEB SITES DESIGN AND EVALUATION}

Once a base is created, it can be used for various evaluation and teaching purposes (e.g., browsing them, searching specific guidelines freely or design question searching, or by teaching, see Fig. 4). A guidelines checklist can gather guidelines previously input by identifying sections relevant for evaluation (e.g., include, exclude, copy, import from various guideline bases).

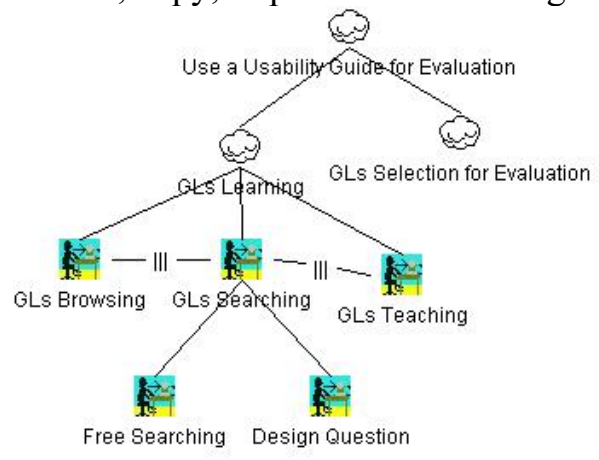

Figure 4. Tasks of Guidelines Learning.

The evaluation reporting task will be totally supported by our tool (Fig. 5 ), by a specific evaluation module, actually under development.

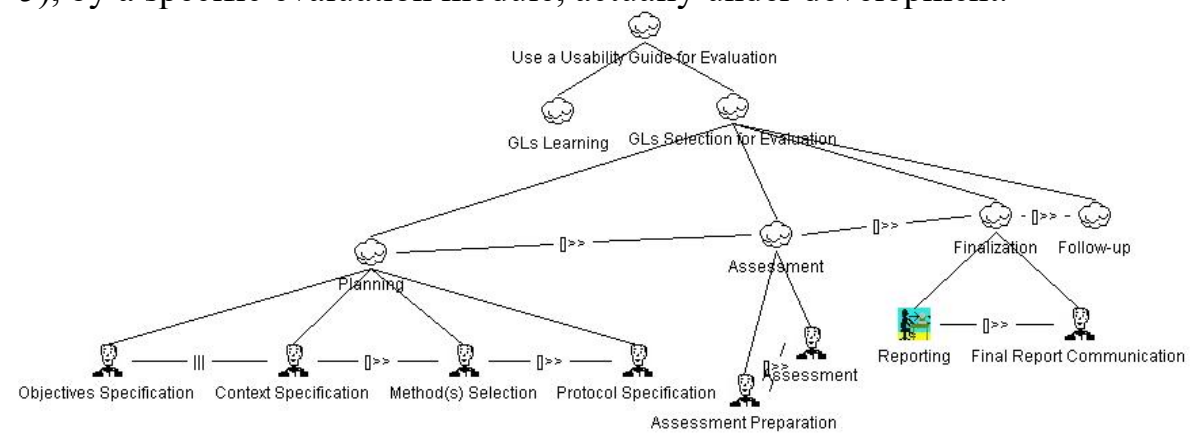

Figure 5. Tasks of Guidelines Use for Evaluation.

This module will permit to the evaluator to choice the information to record in the evaluation task (screen shots, guidelines, scenarios, metainformation about the task like contact information of the evaluator, date, etc.) and to record it when she evaluates her site. The tool supports partially the other evaluation tasks (except the follow-up) by providing information helping the evaluator judgments (e.g., information about which methods to use in such evaluation context). 


\section{THE MetroWeb TOOL}

The tool is intended to support usability guides creation. The created guides are contextualised in order to provide complete information about how to apply the guidelines in a web development cycle. Fig. 6 shows the implemented tool. The tool is developed in Java Swing, on top of Borland Interbase databases, which is open source and can work on multiple platforms. Different views are provided to the user, corresponding to her task.

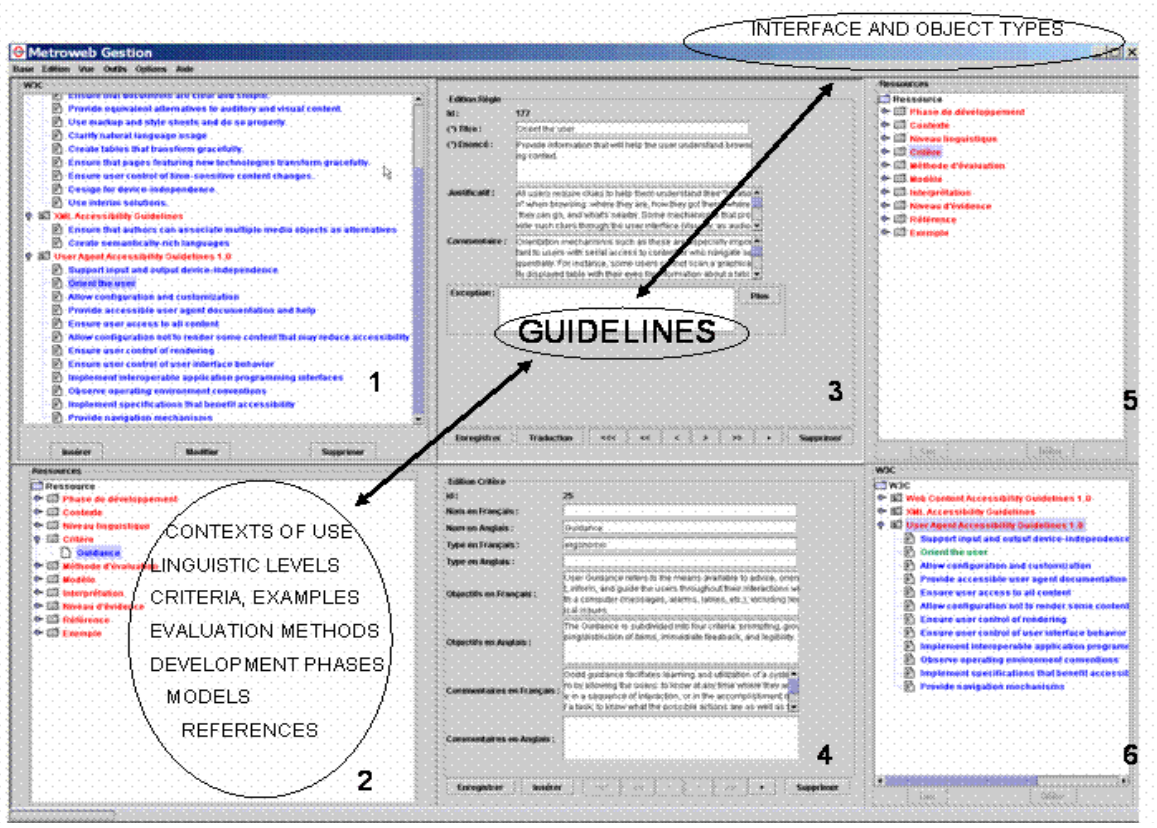

Figure 6. The MetroWeb Tool: complete view.

The complete view (Fig. 6) presents in one screen the guidelines and resources hierarchy, details and links. A guideline is no longer presented isolated from its context of application and related concepts. All the concepts related to the guidelines (Fig. 1), except the interface and objects types, are actually implemented. The left part shows the guidelines hierarchy in bases and sections $(1 \& 2)$. The central part contains details of guidelines and resources linked to guidelines ( $3 \& 4$ ).

The right part contains types of links (and linkage attributes) between guidelines and resources $(5 \& 6)$. Knowledge manipulation is direct because user can move from a specific view to another, directly by moving slide bars. By moving up or down the horizontal slide bar, the complete view (Fig. 6) becomes detailed view of guidelines or resources (Fig. 7), contextualised by it hierarchy and links. 




Figure 7. MetroWeb detailed view.

By moving left or right slide bar, complete view becomes more detailed guidelines or resources views, called normal views (Fig. 8), keeping either it hierarchy or links. These navigation facilities between coordinated views are corresponding to different design and evaluation questions that can be raised frequently in development teams.

At design time, it is possible to quickly identify usability knowledge required to address questions like: "for this interactive task, what are the previous UI implementations (examples) that have been recorded with usability qualities?" (this enables people in an organisation to build an organisation memory of their usability practise over time), "what guidelines do I need to consider to design a form in a web page?", "what are the most important design options impacting usability to be decided at design time?".

At evaluation time, it is possible to find answer to questions like: "what are the guidelines that need to be considered to check this UI against this style guide or standard?", "what should I do to make my web page compliant with W3C Web Accessibility Initiative (WAI) guidelines?", "what level of support can I count on to automate this task?", "Can I use the same guidelines both at design and evaluation time?", "how to store evaluation results so as to reuse them later on?". 


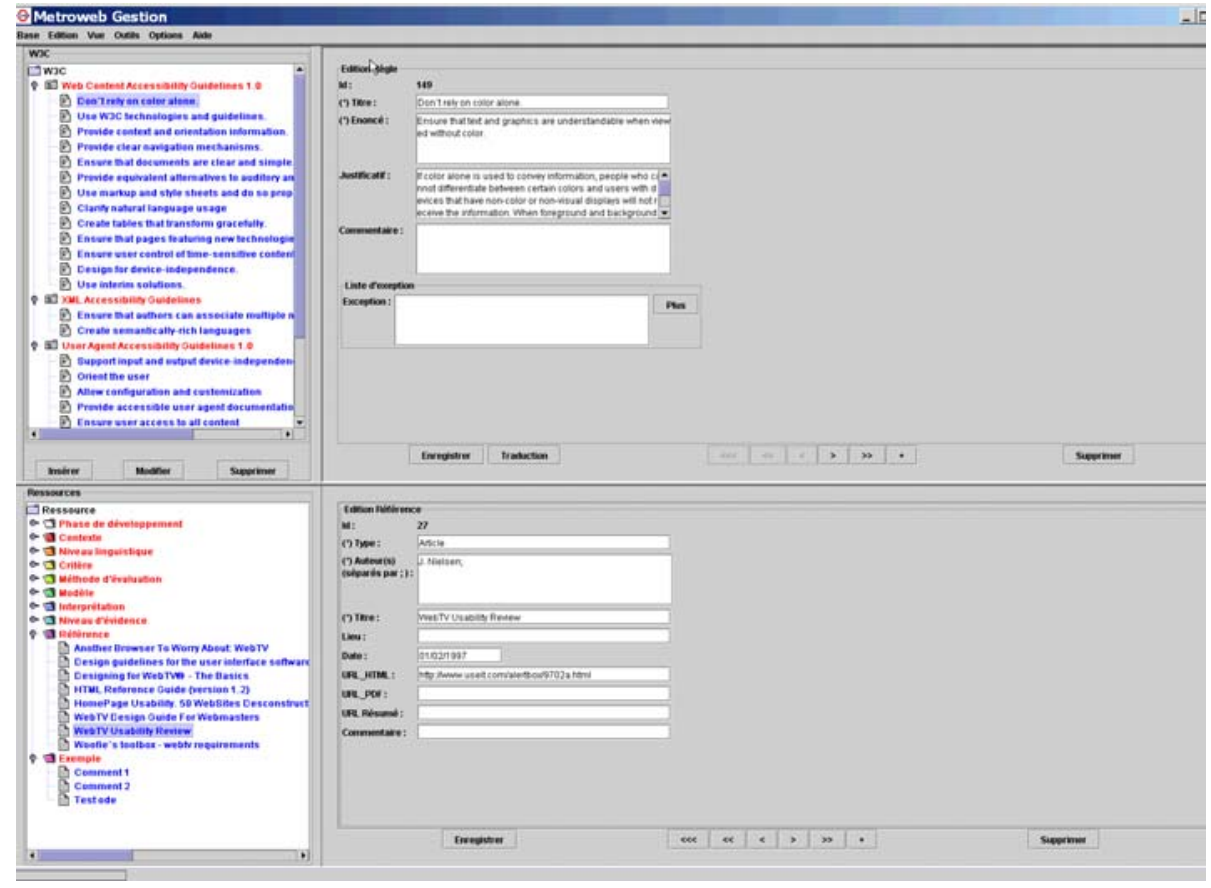

Figure 8. MetroWeb normal view.

\section{CONCLUSION}

The tool presented in this paper permits to support user-centred design and evaluation of web sites, by the creation of multi-bases usability guides, and the use of them during the whole development cycle. The tool, with respect to existing work, is original for the following characteristics: continuity (usability knowledge gathered in the phase of style guide constitution is reused consistently), integration (design and evaluation can be supported simultaneously), multi-bases (multiple knowledge bases can be used at the same time, for instance to evaluate guidelines belonging to different sources), collaboration (since the tool is web-based itself, implemented in Java/Swing, it can be installed and used locally or remotely), level of support (several phases concerning usability in the development life cycle are covered). Our future work concerns the implementation of the evaluation module, aimed to support the usability problems reporting, tightly coupled with a system that supports the designer and the evaluator in automating the evaluation of guidelines contained in METROWEB $[13,14]$. 


\section{REFERENCES}

[1] Bastien, J.M.Ch. and Scapin, D.L., Evaluating a User Interface with Ergonomic Criteria, Research Report, No. 2326, INRIA, August 1994.

[2] Farenc, C., Palanque, P. and Vanderdonckt, J., User Interface Evaluation: is it Ever Us$a b l e$ ?, in Proc. of $6^{\text {th }}$ International Conference on Human-Computer Interaction HCI International'95 (Yokohama, 9-14 July 1995), Elsevier, Amsterdam, 1995, pp. 329-334.

[3] Furtado, E., Furtado, V., Sousa, K., and Belchior, A., An Online Multimedia System for Learning to Design User Interfaces, in Ch. Kolski, J. Vanderdonckt (eds.), Proc. of $3^{\text {rd }}$ Int. Conf. on Computer-Aided Design of User Interfaces CADUI'2002 (Valenciennes, 15-17 May 2002), Kluwer Academic Publishers, Dordrecht, 2002, pp. 229-242.

[4] Grammenos, D., Akoumianakis, D., and Stephanidis, C., Integrated Support for Working With Guidelines: The Sherlock Guidelines Management System, Interacting with Computers, Vol. 12, No. 3, 2000, pp. 281-311.

[5] Henninger, S., A Methodology and Tools for Applying Context-Specific Usability Guidelines to Interface Design, Interacting with Computers, Vol. 12, No. 3, 2000, pp. 225-243.

[6] Mariage, C., Vanderdonckt, J., and Pribeanu, C., State of the Art of Web Usability Guidelines, Chapter 41, in R.W. Proctor, K.-Ph.L. Vu (eds.), " The Handbook of Human Factors in Web Design », Lawrence Erlbaum Associates, Mahwah, 2004.

[7] Nielsen, J., Usability Engineering, Academic Press, Boston, 1993.

[8] Sowa, J.F., Principles of Semantic Network, Morgan Kaufmann, San Mateo, 1991.

[9] Vanderdonckt, J., Accessing Guidelines Information with SIERRA, in Proc. of IFIP TC.13 International Conference on Human-Computer Interaction Interact'95 (Lillehammer, 27-29 June 1995), Chapman \& Hall, London, 1995, pp. 311-316.

[10] Vanderdonckt, J. and Bodart, F., Encapsulating Knowledge for Intelligent Automatic Interaction Objects Selection, in Proc. of the ACM Conf. on Human Factors in Computing Systems INTERCHI'93 (Amsterdam, 24-29 April 1993), ACM Press, New York, 1993, pp. 424-429.

[11] Vanderdonckt, J., Development Milestones towards a Tool for Working with Guidelines, Interacting with Computers, Vol. 12, No. 2, December 1999, pp. 81-118.

[12] Vanderdonckt, J., Visual Design Methods in Interactive Applications, Chapter 7, in M. Albers, B. Mazur (eds.), " Content and Complexity: Information Design in Technical Communication », Lawrence Erlbaum Associates, Mahwah, 2003, pp. 187-203.

[13] Vanderdonckt, J. and Beirekdar, A., The Impact of Internationalization on Guidelines Contents and Usage, in Proceedings of $2^{\text {nd }}$ International Conference on Universal Access in Human-Computer Interaction UAHCI'2003 (Creete, 22-27 June 2003), Vol. 4, C. Stephanidis (ed.), Lawrence Erlbaum Associates, Mahwah, 2003, pp. 1544-1548.

[14] Vanderdonckt, J., Beirekdar, A., Noirhomme-Fraiture, M., Automated Evaluation of Web Usability and Accessibility by Guideline Review, in Proceedings of $4^{\text {th }}$ International Conference on Web Engineering ICWE'04 (Munich, 28-30 July 2004), N. Koch, P. Fraternali, M. Wirsing (eds.), Lecture Notes in Computer Science, Springer-Verlag, Berlin, 2004. 